\title{
Environmental, occupational, and personal factors related to the prevalence of sick building syndrome in the general population
}

\author{
Dan Norbäck, Christer Edling
}

\begin{abstract}
Possible relations between prevalence of sick building syndrome (SBS) and environmental, occupational, and personal factors were studied in a random sample $(0 \cdot 1 \%)$ of the general population aged $20-65$ in a three county region in middle Sweden. Childhood exposure to environmental tobacco smoke from smoking mothers and a childhood in urban areas was related to SBS symptoms. Current urban residency, fresh paint, and preschool children in the dwelling were also related to symptoms. Other residential factors such as age of building, type of building, degree of crowding, mechanical ventilation, or signs of moisture or mould growth were not related to symptoms. Other factors related to symptoms were history of atopy, allergy to nickel, proneness to infection, hyperreactivity, static electricity, work with video display units (VDU), work satisfaction, and climate of cooperation at work. Age, sex, marital state, education level, work stress, obesity, current or earlier smoking, regular physical exercise, or occupational exposure to chemicals did not correlate with symptoms. Women had a higher proportion of symptoms than men but these differences were not significant when adjusting for differences in allergy to nickel, hyperreactivity, and proneness to infection. Maternal smoking was related to a twofold increase of both atopy and allergy to nickel in the adult offspring. Eye symptoms were most common in administrative, managerial, and service work. Airway symptoms were most common in transport and communication work. Dermal symptoms were most common in professional and technical and related work. General symptoms were most common in service, health, hospital,
\end{abstract}

Department of Occupational Medicine, University Hospital, S-751 85 Uppsala, Sweden

Dan Norbäck, Christer Edling and social work. The lowest prevalence of symptoms was found in agricultural, forestry, and sales work. Women and subjects allergic to nickel worked more often in occupations without exposure to chemicals, but no evidence was found for selection mechanisms causing sensitive persons to move from exposed to unexposed occupations. It was concluded that symptoms included in SBS are common in the general population, and of multifactorial origin related to both personal, occupational, and residential factors, and certain environmental exposures such as maternal smoking, the urban environment, VDU work, and volatile organic hydrocarbons from newly painted dwellings.

One new area of occupational and environmental medicine concerns possible health effects related to poor indoor air quality in certain non-industrial buildings, sometimes described as "sick buildings." The sick building syndrome (SBS) is concerned with various non-specific symptoms such as eye, skin, and upper airway irritation, headache, and fatigue. ${ }^{1}$ During recent years, several epidemiological investigations on the causes of SBS have been published..$^{2-15}$ Most of these studies dealt with symptoms among office workers ${ }^{2-10}$ in large cities such as New York, San Francisco, ${ }^{10}$ Copenhagen, ${ }^{78}$ Helsinki, ${ }^{6}$ and Stockholm. ${ }^{25}$ Various factors, such as indoor concentration of volatile organic hydrocarbons, ${ }^{214-16}$ presence of wall to wall carpets ${ }^{1317}$ or fleecy material ${ }^{17}$ age of the building ${ }^{717}$ type of ventilation system, ${ }^{3417}$ degree of crowding, ${ }^{91}$ passive smoking, ${ }^{18}$ moulds, ${ }^{19}$ and building moisture ${ }^{20}$ have been shown to influence the prevalence of SBS symptoms. These symptoms are not uncommon, however, in the general population, ${ }^{1221}$ and may also be influenced by personal factors, ${ }^{81114-15}$ industrial exposure to irritants, ${ }^{12}$ and residential factors. ${ }^{20-21}$ Also concern is growing about possible health effects of childhood exposures to such things as parental smoking, ${ }^{22-26}$ day care outside the home, ${ }^{26-27}$ lead in the urban environment, ${ }^{2829}$ and other environmental pollutants. ${ }^{30-32}$

Our study was performed to consider relations 
between occupational, environmental, and personal factors and the prevalence of SBS symptoms. The main aim was to investigate to what extent relations shown in earlier studies among office workers or young children could be confirmed in a study performed in the general population. A second aim was to study selection mechanisms related to occupational exposure to chemicals and the SBS syndrome.

\section{Material and methods}

The study was carried out in a three county region in mid-Sweden (the counties of Gävleborg, Kopparberg, and Uppsala). The total population in the age group 20-65 in the region was 468000 (162 000 in Gävleborg, 156000 in Kopparberg, and 150000 in Uppsala county). During December 1988, a random sample was drawn from the civil registration register by selecting $0 \cdot 1 \%$ of the total population aged $20-65$. This resulted in a study population of 633 subjects (209 from Gävleborg, 211 from Kopparberg, and 213 from Uppsala county). The study base is the study population observed during a three month period (January-March 1989).

\section{ASSESSMENT OF SYMPTOMS AND PERSONAL FACTORS}

The occurrence of symptoms was recorded by a self administered questionnaire mailed to the 633 subjects in April 1989. The questionnaire requested information on personal factors such as marital state, education level, smoking habits, body weight, body length, regular exercise, atopy, contact allergy, hyperreactivity, sick leave, work stress, work satisfaction, and climate of cooperation at work. It contained questions requiring "yes" or "no" answers on 16 different symptoms and covered the previous three months. No information on the severity or duration of symptoms was gathered. The symptoms were classified as either eye, airway, dermal, or general and the prevalence of subjects with at least one symptom in each group was calculated.

Work stress, work satisfaction, and climate of cooperation were measured with an analogue rating scale as used in earlier studies. ${ }^{11-15} \mathrm{~A}$ psychosocial dissatisfaction index ranging from 0 to $100 \%$ was calculated by adding the perceived degree of work dissatisfaction, work stress, and lack of cooperation at work and dividing by a factor of three. Reference weights were calculated from tables published by Bengston $e t a l^{33}$ and obesity was defined as a body weight exceeding the reference weight by more than $10 \%$. Information on age and sex was obtained from the civil registration register.

ASSESSMENT OF OCCUPATIONAL EXPOSURE

Information on earlier and current occupation was gathered by the questionnaire, which also requested information on the period of the occupations and the name of the workplaces. The questionnaire also requested information on current work with video display units (VDU), environmental tobacco smoke exposure at work, and number of work hours and shift work or night work.

The occupations were classified in accordance with the Nordic Classification of Occupations (NYK 82), which is based on the International Standard Classification of Occupations (ISCO) with a few modifications. ${ }^{34}$ An individual job matrix classification of earlier and current occupational exposure was made by an occupational hygienist with good knowledge of the exposure conditions in the three county region. This classification was performed without any knowledge of symptoms or other information from the questionnaires except current and earlier occupation, job classification codes, period of the occupation, and name of the workplaces. If available, measurements of hygienic exposure from the particular workplaces were used in the classification of exposure.

Each occupation was classified with respect to seven broad classes of chemical exposure-namely, inorganic dust, organic dust, organic solvents, irritating gases, combustion products, animal allergens, and other chemical exposures. Exposure to products of combustion and animal allergens was classified as either exposure or non-exposure. For other types of exposures, the degree of exposure to chemicals was classified into four categories in relation to current Swedish occupational threshold limit values (TLV). ${ }^{35}$ The lowest exposure class (unexposed) was assigned if the subject was occupationally inactive, or if the expected average eight hour exposure was below $10 \%$ of the TLV values for all chemicals assigned to the occupation. The next exposure class was assigned if any of the expected average exposures were above or equal to $10 \%$ but below $100 \%$ of the corresponding TLV value, and without daily peak exposures above the TLV. The third exposure class was assigned if any of the expected average exposures were above or equal to $10 \%$ but below $100 \%$ of the TLV values, and with daily peak exposures above the TLV. The highest exposure class was assigned if any of the expected average exposures were expected to be equal to or to exceed the corresponding TLV value.

Subjects with at least one class of chemicals above or equal to $10 \%$ of TLV were considered "currently exposed." Subjects with a current exposure below $10 \%$ of TLV for all chemicals, were considered "currently unexposed." Currently unexposed subjects with at least one earlier exposure above or equal to $10 \%$ of TLV were considered "earlier exposed." Subjects were considered "never exposed" if all classifications for all their occupations 
were below $10 \%$ of TLV. The current workplaces were also classified as either public sector or private sector, according to the ownership of the building.

\section{ASSESSMENT OF NON-OCCUPATIONAL EXPOSURE}

Information on the address of the subject was obtained from the civil registration register. These addresses were classified into three categories with respect to the degree of urbanisation. The first category comprised rural areas or municipalities with a population below 10000 inhabitants, the second municipalities with a population more than or equal to 10000 but below 50000 , and the third those two municipalities with a population more than or equal to 50000 but below 150000 (the cities of Gävle and Uppsala). In this region, all cities had a population below 150000 .

Information on the dwelling was obtained from the questionnaire. This information comprised type of residence, type of ownership, building age, size of the dwelling and number of adults and children living in the dwelling, type of ventilation system, type of wall material, recent renovation, presence of house pets, moisture damage, and signs of mould growth.

The questionnaire also required information on environmental exposures during the subject's childhood ( $0-5$ years of age). These questions covered parental smoking and child care outside the home. The questionnaire also requested information on the geographical areas and size of the municipalities where the subject lived during the first five years of life.

\section{STATISTICAL METHODS}

Crude odds ratios (ORs) were calculated from fourfold tables and were expressed as significantly enhanced OR $\left(\mathrm{p}<0.05\right.$ calculated by $\chi^{2}$ test for $2 \times 2$ contingency tables). Differences in mean values were calculated by Student's $t$ test.

The influence of different factors on the prevalence of symptoms was analysed by both linear and logistic regression using the EPILOG statistical package. Both regression analyses were performed in seven steps. As a first step, all personal factors were forced into the model. Secondly, all significant personal factors were maintained in the model. Thirdly, nonoccupational exposure variables were forced into the model one by one. As a fourth step, all significant nonoccupational exposure variables were maintained in the model. Fifthly, occupational exposure variables were forced into the model one by one. As a sixth step, all significant occupational exposure variables were maintained in the model. Finally, all nonsignificant variables were excluded.

In all statistical analysis, two tailed tests and a 5\% level of significance were used. Adjusted ORs with a $95 \%$ confidence interval $(95 \% \mathrm{CI})$ were calculated from the logistic regression models.

\section{Results}

The response rate was $70 \%$ among men and $78 \%$ among women. When comparing responders and non-responders with respect to information available from the civil registration register, no significant differences were found between average age, proportion of subjects from the three counties, or degree of urbanisation. The proportion of women, however, was higher among responders compared with nonresponders $(p=0.02)$. When comparing the sample and the total population, however, only a $2 \%$ difference in the proportion of women among responders was found compared with the total population. The proportion of women was $51 \%$ among responders, $41 \%$ among non-responders, and $49 \%$ in the total population. The mean age was 42 (SD 12) among the responders $(n=466)$, and the age distribution was similar among responders and the total population (figure).

During the previous three months, $83 \%$ of the responders were occupationally active. To study possible selection effects of occupational exposure to chemicals, currently exposed, previously exposed, and never exposed subjects were compared with respect to sex, tobacco smoking, atopy, allergy to nickel, hyperreactivity, and proneness to infection (table 1). No significant differences were found between currently exposed and previously exposed subjects. Both currently exposed and previously exposed subjects, however, had a lower prevalence of women and persons with allergy to nickel than those never exposed. Also, currently exposed workers had a lower proportion of never smokers than subjects classified as never exposed to chemicals at work.

Most subjects had spent their childhood in rural areas or small towns in Sweden with day care

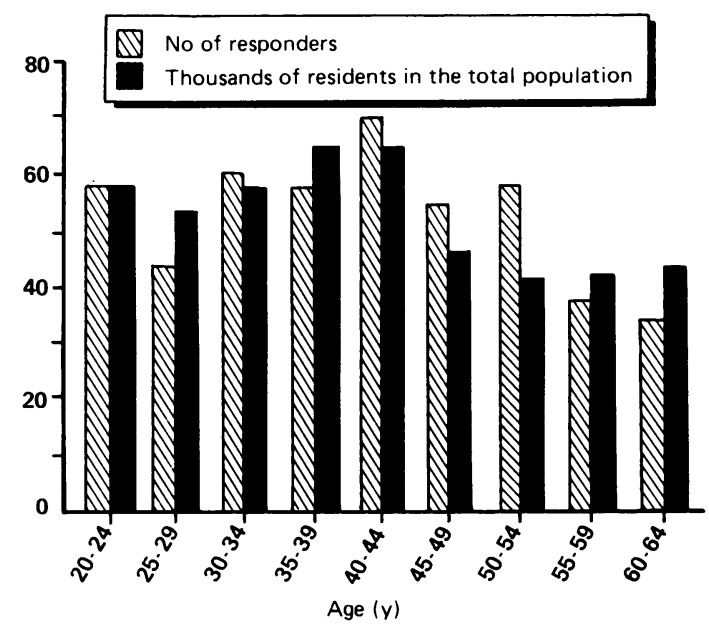

Age distribution of the total population and responders in sample of general population in middle Sweden. 
Table 1 Selected demographic data for occupationally exposed and non-exposed persons in a sample of general population in middle Sweden $(n=466)$

\begin{tabular}{|c|c|c|c|}
\hline Characteristic & $\begin{array}{l}\text { Prevalence in } \\
\text { currently exposed }(\%)+ \\
(n=76)\end{array}$ & $\begin{array}{l}\text { Prevalence in } \\
\text { earlier exposed }(\%)+ \\
(n=79)\end{array}$ & $\begin{array}{l}\text { Prevalence in } \\
\text { never exposed }(\%) \S \\
(n=311)\end{array}$ \\
\hline
\end{tabular}

*Two tailed $\mathrm{p}<0.05 ;{ }^{\star}$ two tailed $\mathrm{p}<0.01 ;{ }^{\star \star \star}$ two tailed $\mathrm{p}<0.001$ all in comparison with never-exposed subjects.

+ Subjects with current average occupational exposure above $10 \%$ of corresponding Swedish occupational TLV for at least one chemical. +Currently unexposed subjects with previous exposure above $10 \%$ of current TLV, in earlier occupations.

$\S$ Subjects never working in occupations with an average exposure above $10 \%$ of current TLV.

Subjects with a history of asthma, hayfever, or eczema in childhood.

$\pi$ Subjects experiencing itch or rashes from dermal contact with base metals (jewellery, buttons, etc).

++ Easily irritated eyes or respiratory tract during exposure to non-specific irritants (tobacco smoke, exhaust gases, organic solvents)

\#Subjects reporting that they often catch a cold or get infections.

provided by the parents (table 2). Environmental exposure to tobacco during the first five years of childhood was common $(19 \%$ of the mothers and $55 \%$ of the fathers were smokers at that time). Most of the subjects lived in detached houses in rural areas or small towns (table 3). Most of the buildings were older houses; the mean age of the buildings was 39 years. Most $(72 \%)$ had mechanical ventilation, usually in the kitchen or in the bathroom. Many $(46 \%)$ were made of wood; $17 \%$ had signs of water damage or building moisture and $5 \%$ of the subjects reported visible moulds or mouldy odour in their dwelling. House pets were common (42\%). Few subjects $(14 \%)$ had preschool children at home. Data on occupational exposure showed that most $(60 \%)$ worked in the private sector. Work with VDUs was common $(26 \%)$. Few subjects were exposed to environmental tobacco smoke or different types of chemical compounds (table 4).

The prevalence of SBS symptoms was in the range of $10-30 \%$ for many common symptoms such as headache, fatigue, and upper airway irritation. Nausea and dermal symptoms were less common (table 5). Table 6 presents the prevalence of symptoms in different occupations. Eye symptoms were least common in sales, transport, and communication work, and most common in administrative, managerial, and service work. Airway symptoms were least

Table 2 Selected demographic and childhood exposure data for a sample of general population in middle Sweden ( $n=466$ )

\begin{tabular}{|c|c|}
\hline Characteristic & Prevalence (No (\%)) \\
\hline $\begin{array}{l}\text { Marital state: } \\
\text { Married } \\
\text { Never married } \\
\text { Divorced } \\
\text { Widow/widower }\end{array}$ & $\begin{array}{l}356(77) \\
73(16) \\
31(7) \\
5(1)\end{array}$ \\
\hline $\begin{array}{l}\text { Education level: } \\
\text { Primary school } \\
\text { Secondary school } \\
\text { University }\end{array}$ & $\begin{array}{l}179(38) \\
186(40) \\
202(22)\end{array}$ \\
\hline $\begin{array}{l}\text { Regular physical exercise: } \\
\text { Less than } 1 \mathrm{~h} / \text { week } \\
\text { Moderate exercise }>1 \mathrm{~h} / \text { week } \\
\text { Strenuous exercise }>1 \mathrm{~h} / \text { week }\end{array}$ & $\begin{array}{c}226(50) \\
202(44) \\
26(6)\end{array}$ \\
\hline Obesity ( $>10 \%$ of mean weight) & $80(17)$ \\
\hline $\begin{array}{l}\text { Childhood }(<5 \text { y) residency in: } \\
\text { Rural area } \\
\text { Town }(<10000 \text { inhabitants }) \\
\text { Small city }(10000-100000 \text { inhabitants }) \\
\text { Large city ( }>100000 \text { inhabitants })\end{array}$ & $\begin{array}{r}177(38) \\
135(29) \\
99(21) \\
50(11)\end{array}$ \\
\hline $\begin{array}{l}\text { Childhood childcare ( < five years old): } \\
\text { By parents in the child's own home } \\
\text { In other home environments } \\
\text { In day care centres }\end{array}$ & $\begin{array}{l}413(89) \\
40(9) \\
7(2)\end{array}$ \\
\hline $\begin{array}{l}\text { Maternal smoking during childhood (< five years old) } \\
\text { Paternal smoking during childhood (< five years old) } \\
\text { Childhood ( }<\text { five years old) outside Sweden }\end{array}$ & $\begin{array}{r}85(19) \\
252(55) \\
43(9)\end{array}$ \\
\hline
\end{tabular}


Table 3 Selected residential data for a sample of general population in middle Sweden $(n=466)$

\begin{tabular}{lc}
\hline Characteristic & Prevalence (No(\%)) \\
\hline Site of residency: & $207(44)$ \\
Rural area/town <10 000 inhabitants & $142(30)$ \\
Town (10 000 to 50000 inhabitants) & $117(25)$ \\
City (50 000 to 150000 inhabitants) & $388(86)$ \\
No of small children (<five years old) at home: & $47(10)$ \\
None & $17(4)$ \\
One & $0(0)$ \\
Two & $103(24)$ \\
More than two & $263(56)$ \\
Current dwelling: & $218(46)$ \\
New building (built after 1974) & $194(42)$ \\
Wooded house & $24(5)$ \\
House pets (furry animals or birds) in dwelling & $80(17)$ \\
Mouldy odour or visible signs of indoor moulds & $121(26)$ \\
Water damage or signs of building moisture & \\
Interior of dwelling painted during last year & $126(28)$ \\
Type of ventilation in dwelling: & $265(59)$ \\
Natural ventilation only & $61(13)$ \\
Mechanical ventilation in kitchen ibathroom only &
\end{tabular}

common in agricultural or forestry work, and most common in transport and communication work. Dermal symptoms were least common in agricultural, forestry, transport, and communications work, and most common in professional and technical and related work. General symptoms were least common in sales, agricultural, and forestry work, and most common in service, health, hospital, and social work.

Initially, women reported a significantly higher prevalence of airways symptoms $(O R=1.7$; $\mathrm{p}<0.01)$, dermal symptoms $(\mathrm{OR}=1.7 ; \mathrm{p}<0.05)$, and general symptoms $(O R=1.6 ; p<0.01)$. They also reported a higher prevalence of allergy to nickel $(\mathrm{OR}=24.2 ; \quad \mathrm{p}<0.001)$, non-specific hyper- reactivity $(\mathrm{OR}=1.7 ; \mathrm{p}<0.01)$, and proneness to infection (OR $=1.8 ; \mathrm{p}<0.05)$. After adjusting for these three factors in the final regression models, no significant differences in symptom prevalences between men and women could be shown.

Both logistic and linear regression analyses showed that three personal and one childhood exposure factor were related to the prevalence of eye symptoms-namely, proneness to infection ( $p<0.001$ ), atopy $(\mathrm{p}<0.001)$, non-specific hyperreactivity ( $p<0.001$ ), and exposure to tobacco smoke in childhood from smoking mothers ( $p<0.05$; table 7$)$. Similar analyses showed that three personal factors and two non-occupational exposures were signifi-

Table 4 Occupational exposure data for a sample of occupational active population in middle Sweden ( $n=384$ )

\begin{tabular}{|c|c|}
\hline Characteristic & Prevalence (No (\%)) \\
\hline $\begin{array}{l}\text { Private sector workplace } \\
\text { Public sector workplace } \\
\text { Shift or night work } \\
\text { Work with VDUs } \\
\text { Occupational contact with animals } \\
\text { Environmental tobacco smoke exposure at work } \\
\text { Occupational exposure to combustion products } \\
\text { Occupational exposure to static electricity }\end{array}$ & $\begin{array}{r}230(60) \\
154(40) \\
70(18) \\
101(26) \\
13(3) \\
50(13) \\
37(8) \\
43(11)\end{array}$ \\
\hline $\begin{array}{l}\text { Inorganic dust: } \\
\text { Mean exposure above } 10 \% \text { of TLV } \\
\text { Daily peak exposure above TLV }\end{array}$ & $\begin{array}{l}45(12) \\
21(5)\end{array}$ \\
\hline $\begin{array}{l}\text { Organic dust: } \\
\text { Mean exposure above } 10 \% \text { of TLV } \\
\text { Daily peak exposure above TLV }\end{array}$ & $\begin{array}{l}35(9) \\
29(8)\end{array}$ \\
\hline $\begin{array}{l}\text { Organic solvents: } \\
\text { Mean exposure above } 10 \% \text { of TLV } \\
\text { Daily peak exposures above TLV }\end{array}$ & $\begin{array}{r}32(8) \\
6(2)\end{array}$ \\
\hline $\begin{array}{l}\text { Irritating gases: } \\
\text { Mean exposure above } 10 \% \text { of TLV } \\
\text { Daily peak exposure above TLV }\end{array}$ & $\begin{array}{r}19(4) \\
5(1)\end{array}$ \\
\hline $\begin{array}{l}\text { Other chemical compounds: } \\
\text { Mean exposure above } 10 \% \text { of TLV } \\
\text { Daily peak exposure above TLV }\end{array}$ & $\begin{array}{l}9(2) \\
1(0 \cdot 2)\end{array}$ \\
\hline
\end{tabular}


Table 5 Three month prevalence of symptoms in a sample of general population $(n=466)$ in a mid-Swedish three county region

\begin{tabular}{lc}
\hline Type of symptom & $\begin{array}{c}\text { Prevalence of } \\
\text { symptoms (\%) }\end{array}$ \\
\hline Eye irritation & 16 \\
Swollen eyelids & 6 \\
Nasal catarrh & 15 \\
Blocked up nose & 19 \\
Dryness in the throat & 13 \\
Sore throat & 10 \\
Irritative cough & 10 \\
Headache & 19 \\
Abnormal tiredness & 30 \\
Sensation of getting a cold & 23 \\
Nausea & 7 \\
Facial itching & 6 \\
Facial rash & 6 \\
Itching on the hands & 9 \\
Rashes on the hands & 8 \\
Eczema & 11 \\
\hline
\end{tabular}

cantly related to airway symptoms in both regression models-namely, proneness to infection (p<0.001), atopy $(\mathrm{p}<0.001)$, non-specific hyperreactivity $(\mathrm{p}<0.001)$, current urban residency $(p<0.05)$, and exposure to fresh paint in the dwelling during the last year $(\mathrm{p}<0.05)$ (table 8).

Multiple regression analysis of dermal symptoms showed that atopy $(\mathrm{p}<0.001)$, hyperreactivity $(\mathrm{p}<0.01)$, and allergy to nickel $(\mathrm{p}<0.05)$ were related to such symptoms (table 9 ). Three personal and two environmental factors were related to the prevalence of general symptoms - namely, proneness to infection $(\mathrm{p}<0.001)$, non-specific hyperreactivity ( $p<0.05)$, allergy to nickel $(p<0.05)$, urban residency in childhood $(p<0.01)$, and number of preschool children in current dwelling $(p<0.05)$ (table 10). Table 11 presents the adjusted ORs calculated from the logistic regression models for significant personal factors and non-occupational exposures.

Childhood exposure to tobacco smoke from smoking mothers was related to eye symptoms (table 7). A relation also existed between maternal smoking and both atopy $(\mathrm{OR}=2.0 ; \mathrm{p}<0.01)$, and allergy to nickel $(\mathrm{OR}=2.4 ; \mathrm{p}<0.01)$. Among subjects with non-smoking mothers, the prevalence of atopy was $22 \%$ and the prevalence of allergy to nickel was $14 \%$. The corresponding prevalences for subjects with smoking mothers were $35 \%$ for atopy and $28 \%$ for allergy to nickel. No relation between the fathers' smoking habits and atopy or allergy to nickel was found. No significant relation was seen between the subjects' current smoking habits and the mothers' or fathers' smoking habits. Maternal smoking, however, was more common in urban areas. Among subjects who had spent their childhood in rural areas, only $8 \%$ had smoking mothers, whereas $44 \%$ of those growing up in larger cities $(>100000$ inhabitants) had smoking mothers ( $p<0.001)$. Because atopy and allergy to nickel could be induced by maternal smoking, these two factors were excluded from the model when calculating the ORs for SBS symptoms and maternal smoking presented in table 11. By excluding these two factors a significant relation between maternal smoking and airway, eye, and general symptoms was found $(p<0.05)$. The exclusion of atopy and allergy to nickel also resulted in somewhat higher ORs for eye symptoms and maternal smoking $(\mathrm{OR}=2.3 \mathrm{com}$ pared with $\mathrm{OR}=2.0$ when adjusting for atopy and allergy to nickel in the regression models).

Further analysis of the relation between occupational factors and symptoms showed that VDU work was related to both eye symptoms and dermal symptoms $(p<0.01)$, and also self reported exposure to static electricity was related to eye symptoms $(p<0.001)$. Initially, we found a relation between general symptoms and the psychosocial dissatisfaction index $(p<0.01)$. Different aspects of the psychosocial climate, however, were found to have different influences on symptoms. Poor work satisfaction was related to a higher prevalence of

Table 6 Three month prevalence (\%) of symptoms in different types of occupations (NYK classification) $(n=465)$ *

\begin{tabular}{|c|c|c|c|c|c|}
\hline \multirow[b]{2}{*}{ Type of occupation } & \multicolumn{5}{|c|}{ Type of symptoms } \\
\hline & No & Eye $(\%) \dagger$ & Airway (\%) & Dermal (\%)§ & General (\%) \\
\hline $\begin{array}{l}\text { Professional, technical, and related work (0) } \\
\text { Health, hospital, and social work (1) } \\
\text { Administrative and managerial work (2) } \\
\text { Sales work (3) } \\
\text { Agricultural and forestry work (4) } \\
\text { Transport and communications work (6) } \\
\text { Production work (7-8) } \\
\text { Service work (9) } \\
\text { Occupationally inactive subjects }\end{array}$ & $\begin{array}{l}74 \\
69 \\
66 \\
19 \\
19 \\
25 \\
80 \\
35 \\
78\end{array}$ & $\begin{array}{r}18 \\
20 \\
23 \\
5 \\
11 \\
4 \\
18 \\
29 \\
13\end{array}$ & $\begin{array}{l}36 \\
36 \\
30 \\
26 \\
16 \\
44 \\
30 \\
31 \\
26\end{array}$ & $\begin{array}{r}31 \\
25 \\
23 \\
26 \\
16 \\
8 \\
15 \\
20 \\
16\end{array}$ & $\begin{array}{l}43 \\
55 \\
42 \\
21 \\
26 \\
48 \\
39 \\
51 \\
46\end{array}$ \\
\hline
\end{tabular}

*One subject in mining/quarrying work (5.) excluded from the table.

+Eye irritation or swollen eyelids.

${ }_{+}^{+}$Nasal catarrh, blocked up nose, dry or sore throat, or irritative cough.

Eczema, facial itching, facial rash, itching or rashes on the hands.

Headache, abnormal tiredness, sensation of getting a cold or nausea. 
Table 7 Regression analysis of prevalence of at least one eye symptom in general population $(n=434) \dagger$ as a function of three significant personal factors and one significant exposure variable $(p<0.05)$

\begin{tabular}{|c|c|c|}
\hline Variable & $\begin{array}{l}\text { Logistic model } \\
\text { (coefficient }(S E) \text { ) }\end{array}$ & $\begin{array}{l}\text { Linear model } \\
(\text { coefficient }(S E))\end{array}$ \\
\hline $\begin{array}{l}\text { Atopy }+ \\
\text { Proneness to infection }+ \\
\text { Hyperreactivity }+ \\
\text { Maternal smoking } \\
\text { Constant }\end{array}$ & $\begin{array}{l}1 \cdot 34^{\star \star \star}(0 \cdot 28) \\
1 \cdot 30^{\star \star \star}(0 \cdot 33) \\
1 \cdot 07^{\star \star \star}(0 \cdot 28) \\
0 \cdot 68^{\star}(0 \cdot 31) \\
-2 \cdot 82\end{array}$ & $\begin{array}{l}0.20^{\star \star \star}(0.040) \\
0 \cdot 21^{\star \star \star}(0.051) \\
0 \cdot 16^{\star \star \star}(0.038) \\
0.092^{\star}(0.043) \\
0.03\end{array}$ \\
\hline
\end{tabular}

«Two tailed $\mathrm{p}<0.05 ; \star \star \star$ two tailed $\mathrm{p}<0.001$.

$\mathrm{SE}=$ Standard error of coefficient.

tIncomplete answers from 32 subjects.

$+0=$ Absence, $1=$ presence.

Nine personal factors were non-significant $(p>0.05)$ predictors of eye symptoms-namely, age, sex, marital state, education level, allergy to nickel, current tobacco smoking, earlier tobacco smoking, weight index, and regular physical exercise.

Four childhood exposures were non-significant predictors of eye symptoms-namely, paternal smoking during childhood, childcare outside the home, childhood residency outside Sweden, and childhood residency in urban areas.

Ten current residential exposures were non-significant predictors of eye symptoms-namely, residency in urban areas, age of dwelling, population density in the dwelling, type of dwelling (flat/own house), wall material (wood/stone), mechanical ventilation, moisture damage or mould growth, newly painted interior, presence of house pets, and number of preschool children at home.

general symptoms $(\mathrm{p}<0.0001)$. Poor climate of cooperation at work was related to eye symptoms $(\mathrm{p}<0.001)$ and general symptoms $(\mathrm{p}<0.001)$. No significant relation was found between degree of work stress and any type of symptom. Other factors such as night or shift work, public sector work, occupational activity, or exposure to environmental tobacco smoke, combustion products, organic or inorganic dust, organic solvents, irritating gases, or occupational contact with animals were not related to symptoms. Table 12 presents the adjusted ORs with $95 \%$ CIs for occupational exposures.

\section{Discussion}

These results indicate a relation between SBS symptoms and urban residency, VDU work, static electricity, psychosocial work environment, exposure to fresh paint, and presence of preschool children at home. Furthermore, childhood exposure to maternal tobacco smoke and urban environments might enhance the prevalence of SBS symptoms. Also, a relation was shown between maternal smoking and atopy as well as allergy to nickel among adults.

Many methodological problems are inherent in an epidemiological study, particularly with regard to internal validity. Selection bias can occur as a result of both a low response rate and incorrect study design. The subjects included in this study were randomly selected from the civil registration register. These registers have a high quality and the proportion of subjects not found in the registers is negligible. The non-response rate was $26 \%$ and thus a selection bias could occur. No difference in age or degree of urbanisation occurred, however, between responders and non-responders. Also the proportion of occupationally active responders $(83 \%)$ was nearly identical to the proportion of occupationally active

Table 8 Regression analysis of prevalence of at least one airway symptom in general population $(n=446) \dagger$ as a function of three significant personal factors and three significant exposure variables $(p<0.05)$

\begin{tabular}{|c|c|c|}
\hline Variable & $\begin{array}{l}\text { Logistic model } \\
\text { (coefficient }(S E))\end{array}$ & $\begin{array}{l}\text { Linear model } \\
\text { (coefficient }(S E))\end{array}$ \\
\hline $\begin{array}{l}\text { Atopy }+ \\
\text { Hyperreactivity } \\
\text { Proneness to infection }+ \\
\text { Current urban residency§ } \\
\text { Childhood residency abroad }+ \\
\text { Dwelling painted during last year }+ \\
\text { Constant }\end{array}$ & $\begin{array}{l}0 \cdot 87^{\star \star}(0 \cdot 27) \\
0 \cdot 96^{\star \star \star}(0 \cdot 26) \\
3 \cdot 39^{\star \star \star}(0 \cdot 46) \\
0 \cdot 30^{\star}(0 \cdot 14) \\
\text { NS } \\
0 \cdot 66^{\star}(0 \cdot 26) \\
-2 \cdot 21\end{array}$ & $\begin{array}{l}0 \cdot 15^{\star \star \star}(0 \cdot 044) \\
0 \cdot 14^{\star \star \star}(0 \cdot 044) \\
0 \cdot 62^{\star \star \star}(0 \cdot 056) \\
0 \cdot 044^{\star}(0 \cdot 023) \\
0 \cdot 14^{\star}(0 \cdot 064) \\
0 \cdot 11^{\star}(0 \cdot 042) \\
0 \cdot 21\end{array}$ \\
\hline
\end{tabular}

$\star$ Two tailed $\mathrm{p}<0.05 ;{ }^{\star}$ two tailed $\mathrm{p}<0.01 ; \star \star \star$ two tailed $\mathrm{p}<0.001$

$\mathrm{SE}=$ Standard error of coefficient; NS = non-significant.

+ Incomplete answers from 20 subjects.

$+0=$ Absence, 1 = presence.

$\$ 0=$ Rural area or town with $<10000$ inhabitants, $1=$ town with $10000-50000$ inhabitants, $2=$ city with $50000-150000$ inhabitants.

Nine personal factors were non-significant $(p>0.05)$ predictors of airway symptoms-namely, age, sex, marital state, education level, weight index, regular physical exercise, current tobacco smoking, earlier tobacco smoking, and allergy to nickel.

Four childhood exposures were non-significant predictors of airway symptoms-namely, maternal smoking during childhood, paternal smoking during childhood, childcare outside the home, and childhood residency in urban areas.

Eight current residential exposures were non-significant predictors of airway symptoms-namely, age of dwelling, population density in the dwelling, type of dwelling (flat/own house), wall material (wood/stone), mechanical ventilation, moisture damage or mould growth, presence of house pets, and number of preschool children at home. 
Table 9 Regression analysis of prevalence of at least one dermal symptom in general population $(n=451) \dagger$ as a function of three significant personal factors $(p<0.05)$

\begin{tabular}{|c|c|c|}
\hline Variable & $\begin{array}{l}\text { Logistic model } \\
\text { (coefficient }(S E))\end{array}$ & $\begin{array}{l}\text { Linear model } \\
\text { (coefficient }(S E) \text { ) }\end{array}$ \\
\hline $\begin{array}{l}\text { Atopy }+ \\
\text { Hyperreactivity } \ddagger \\
\text { Allergy to nickel }+ \\
\text { Constant }\end{array}$ & $\begin{array}{l}0.99^{\star \star \star}(0 \cdot 25) \\
0.75^{\star \star}(0 \cdot 25) \\
0.70^{\star}(0 \cdot 29) \\
-2 \cdot 03\end{array}$ & $\begin{array}{l}0 \cdot 17^{\star \star \star}(0.043) \\
0 \cdot 11^{\star \star}(0 \cdot 040) \\
0 \cdot 12^{\star}(0.050) \\
-0.02\end{array}$ \\
\hline
\end{tabular}

*Two tailed $\mathrm{p}<0.05 ;{ }^{\star \star}$ two tailed $\mathrm{p}<0.01 ;{ }^{\star \star \star}$ two tailed $\mathrm{p}<0.001$.

$\mathrm{SE}=$ Standard error of coefficient.

+ Incomplete answers from 15 subjects.

$+0=$ Absence, 1 = presence.

Nine personal factors were non-significant $(p>0.05)$ predictors of dermal symptoms-namely, age, sex, marital state, education level, current tobacco smoking, earlier tobacco smoking, proneness to infection, weight index, regular exercise.

Five childhood exposures were non-significant predictors of dermal symptoms-namely, maternal smoking during childhood, paternal smoking during childhood, childcare outside the home, childhood residency outside Sweden, and childhood residency in urban areas.

'Ten current residential exposures were non-significant predictors of dermal symptoms-namely, residency in urban areas, age of dwelling, population density in the dwelling, type of dwelling (flat/own house), wall material (wood/stone), mechanical ventilation, moisture damage or mould growth, newly painted interior, presence of house pets, and number of preschool children at home.

subjects $(82 \%)$ in the total population..$^{36}$ The proportion of women, however, was higher in responders than in non-responders. As only a $2 \%$ difference existed in the proportion of women between responders and the total population, we consider this overrepresentation of women to be of minor significance.

The study base covered both occupationally active and inactive subjects, and retrospective exposure information was gathered. This design made it possible to detect selection effects, which a crosssectional study comparing an exposed and nonexposed group of workers would not be able to study. Although women and subjects with allergy to nickel more often avoided occupations with chemical exposures, we were not able to show any selection effects of occupational chemical exposure causing sensitive subjects to move from exposed to nonexposed occupations.
Response bias due to awareness of the exposure may also influence the result when information on both exposure and outcome variables are gathered by questionnaires. We found, however, relations only for specific exposures and specific types of symptoms. Another problem is the possible response bias related to retrospective exposure information such as maternal smoking and earlier occupations. In two earlier investigations, questions on parental smoking have been validated by comparing the subjects' answers with information from other sources. ${ }^{37}{ }^{38}$ Both studies showed that people can reliably recall whether or not their parents smoked but they cannot accurately recall the amount of smoking. In a Swedish thesis, retrospective occupational history obtained by retrospective interview questions was compared with prospective occupational information obtained from censuses. ${ }^{39} \mathrm{~A}$ good agreement was found between self reported occupational history and census data.

Table 10 Regression analysis of prevalence of at least one general symptom in general population $(n=439)+$ as a function of three significant personal factors and two significant exposure variables $(p<0.05)$

\begin{tabular}{|c|c|c|}
\hline Variable & $\begin{array}{l}\text { Logistic model } \\
\text { (coefficient (SE)) }\end{array}$ & $\begin{array}{l}\text { Linear model } \\
\text { (coefficient }(S E))\end{array}$ \\
\hline $\begin{array}{l}\text { Infection proneness }+ \\
\text { Hyperreactivity } \\
\text { Allergy to nickel+ } \\
\text { Childhood urban residency } \\
\text { Preschool children at home } \\
\text { Constant }\end{array}$ & $\begin{array}{l}3 \cdot 15^{\star \star \star}(0 \cdot 53) \\
0 \cdot 63^{\star \star}(0 \cdot 24) \\
0 \cdot 77^{\star \star}(0 \cdot 30) \\
0 \cdot 28^{\star \star}(0 \cdot 10) \\
0 \cdot 51^{\star}(0 \cdot 22) \\
-1 \cdot 25\end{array}$ & $\begin{array}{l}0 \cdot 50^{\star \star \star}(0 \cdot 067) \\
0 \cdot 10^{\star}(0 \cdot 049) \\
0 \cdot 14^{\star}(0 \cdot 059) \\
0 \cdot 057^{\star \star}(0 \cdot 021) \\
0 \cdot 10^{\star}(0 \cdot 045) \\
0 \cdot 24\end{array}$ \\
\hline
\end{tabular}

$\star T$ wo tailed $\mathrm{p}<0.05 ;{ }^{\star}$ two tailed $\mathrm{p}<0.01 ;{ }^{\star \star \star}$ two tailed $\mathrm{p}<0.001$.

$\mathrm{SE}=$ Standard error of coefficient.

†Incomplete answers from 27 subjects.

$+0=$ Absence, $1=$ presence.

$\$ 0=$ Rural area; $1=$ town ( $<10000$ inhabitants); $2=$ small city $(10000-100000$ inhabitants $) ; 3=$ larger city $(>100000$ inhabitants $)$.

Number of preschool children ( $<$ five years old) at home.

Nine personal factors were non-significant $(p>0.05)$ predictors of general symptoms-namely, age, sex, atopy, marital state, education level, current tobacco smoking, earlier tobacco smoking, weight index, and regular physical exercise.

Four childhood exposures were non-significant predictors of airway symptoms-namely, maternal smoking during childhood, paternal smoking during childhood, childcare outside the home, and childhood residency in urban areas.

Nine current residential exposures were non-significant predictors of general symptoms-namely, residency in urban areas, age of dwelling, population density in the dwelling, type of dwelling (flat/own house), wall material (wood/stone), mechanical ventilation, moisture damage or mould growth, newly painted interior, and presence of house pets. 
Table 11 Adjusted ORs (95\% CI) for significant personal factors and non-occupational exposures in the general population $(n=466)$

\begin{tabular}{|c|c|c|c|c|}
\hline \multirow[b]{2}{*}{ Type of factor } & \multicolumn{4}{|c|}{ Type of symptoms } \\
\hline & $E y e^{\star}$ & Airwayt & Dermalt & Generals \\
\hline $\begin{array}{l}\text { Proneness to infection } \\
\text { Atopy } \\
\text { Allergy to nickel } \\
\text { Hyperreactivity } \\
\text { Maternal smoking } \\
\text { Urban childhood ( }>10000 \text { inhabitants) } \\
\text { Current urban residency ( }>10000 \text { inhabitants) } \\
\text { Newly painted dwelling } \\
\text { Preschool children at home }\end{array}$ & $\begin{array}{l}3 \cdot 7(2 \cdot 0-7 \cdot 0) \\
3 \cdot 8(2 \cdot 2-6 \cdot 6) \\
1 \cdot 3(0 \cdot 7-2 \cdot 5) \\
2 \cdot 9(1 \cdot 7-5 \cdot 0) \\
2 \cdot 3(1 \cdot 3-4 \cdot 1) \\
1.5(0 \cdot 9-2 \cdot 6) \\
1 \cdot 3(0 \cdot 7-2 \cdot 2) \\
1.6(0 \cdot 9-3 \cdot 0) \\
0.6(0 \cdot 2-1 \cdot 3)\end{array}$ & $\begin{array}{l}29.4(12-72) \\
2 \cdot 4(1 \cdot 4-4 \cdot 1) \\
1 \cdot 8(0 \cdot 99-4 \cdot 1) \\
2 \cdot 7(1 \cdot 6-4 \cdot 4) \\
1.9(1 \cdot 1-3 \cdot 4) \\
1.5(0.9-2 \cdot 5) \\
1.7(1.02-2 \cdot 7) \\
1.9(1 \cdot 1-3 \cdot 2) \\
0.7(0.5-1 \cdot 3)\end{array}$ & $\begin{array}{l}1 \cdot 3(0 \cdot 7-2 \cdot 5) \\
2 \cdot 7(1 \cdot 6-4 \cdot 4) \\
2 \cdot 0(1 \cdot 1-3 \cdot 5) \\
2 \cdot 1(1 \cdot 3-3 \cdot 4) \\
0 \cdot 8(0 \cdot 4-1 \cdot 5) \\
1 \cdot 6(0 \cdot 95-2 \cdot 5) \\
1 \cdot 1(0 \cdot 7-1 \cdot 7) \\
1 \cdot 2(0 \cdot 7-2 \cdot 0) \\
1 \cdot 2(0 \cdot 6-2 \cdot 4)\end{array}$ & $\begin{array}{l}23 \cdot 3(8 \cdot 0-66) \\
1 \cdot 1(0 \cdot 7-1 \cdot 7) \\
2 \cdot 2(1 \cdot 2-3 \cdot 9) \\
1 \cdot 9(1 \cdot 2-3 \cdot 0) \\
1 \cdot 8(1 \cdot 01-3 \cdot 0) \\
1 \cdot 6(1 \cdot 1-2 \cdot 5) \\
1 \cdot 1(0 \cdot 7-1 \cdot 7) \\
1 \cdot 1(0 \cdot 7-1 \cdot 8) \\
2 \cdot 0(1 \cdot 1-3 \cdot 5)\end{array}$ \\
\hline
\end{tabular}

^Eye irritation or swollen eyelids.

+Nasal catarrh, blocked up nose, dry or sore throat or irritative cough.

+ Eczema, facial itching, facial rash, itching or rashes on the hands.

\$eadache, abnormal tiredness, sensation of getting a cold or nausea.

Adjusted for all significant factors except allergy to nickel and atopy.

Moreover, similar morbidity patterns were obtained for different exposure categories constructed by a job exposure matrix either from a retrospective interview or longitudinally through censuses.

Finally, in multivariate modelling of epidemiological data, the type of regression model ${ }^{40}$ or mass significance may influence the results. In our study, both linear and logistic regression analysis resulted in the same significant parameters, except in one case. With regard to the discussed aspects of internal validity, we do not think that the results of our study are due to response bias, selection bias, mass significance, or the selection of a particular regression model.

Proneness to infection was strongly related to both eye, airway, and general symptoms. In an earlier study we found that sick leave due to airway illness was related to prevalence of symptoms in sick buildings. ${ }^{14}$ Also, changes in the frequency of sick leave owing to respiratory illness corresponded to changes of sick building symptoms among primary school personnel. ${ }^{15}$

Signs of hyperreactivity were related to eye, airway, dermal, and general symptoms. In two of our earlier studies, self reported hyperreactivity was related to SBS symptoms in sick buildings ${ }^{14}$ and primary school personnel..$^{15}$ Besides hyperreactivity, atopy and allergy to nickel were also related to the prevalence of SBS symptoms.

Allergy to nickel is the most common contact allergy in Sweden. ${ }^{41}$ The question used in our questionnaire was selected since it was found to be the single question best related to a positive patch test to nickel $(67 \%$ sensitivity and $97 \%$ specificity; L Widström, personal communication). We found that nickel is a predictor not only of dermal symptoms but also of general symptoms. Moreover, selection effects in relation to occupational exposure to chemicals seem to be related to this contact allergy rather than to IgE mediated atopy.

Table 12 Adjusted ORs (95\% CI) for occupational exposures and type of symptoms

\begin{tabular}{|c|c|c|c|c|}
\hline \multirow[b]{2}{*}{ Type of exposure } & \multicolumn{4}{|c|}{ Type of symptoms } \\
\hline & Eye & Airway† & Dermal + & General\$ \\
\hline $\begin{array}{l}\text { Psychosocial dissatisfaction index } \\
\text { Work stress } \\
\text { Work dissatisfaction } \\
\text { Poor climate of cooperation at work } \\
\text { Work with video display terminals } \\
\text { Electrostatically charged at work } \\
\text { Environmental tobacco smoke at work } \\
\text { Current chemical exposure at work } \\
\text { Earlier chemical exposure at work } \\
\text { Public sector workplace } \\
\text { Night work or shift work } \\
\text { Occupationally activeI }\end{array}$ & $\begin{array}{l}2 \cdot 0(0 \cdot 6-7 \cdot 3) \\
1 \cdot 2(0 \cdot 4-3 \cdot 9) \\
3 \cdot 4(0 \cdot 9-12) \\
4 \cdot 7(1 \cdot 4-16) \\
1 \cdot 6(1 \cdot 03-2 \cdot 5) \\
1 \cdot 9(1 \cdot 1-3 \cdot 2) \\
1 \cdot 3(0 \cdot 8-2 \cdot 2) \\
1 \cdot 3(0 \cdot 6-2 \cdot 7) \\
1 \cdot 1(0 \cdot 6-2 \cdot 1) \\
1 \cdot 0(0 \cdot 6-1 \cdot 7) \\
1 \cdot 1(0 \cdot 5-2 \cdot 2) \\
1 \cdot 3(0 \cdot 6-2 \cdot 8)\end{array}$ & 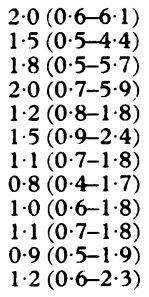 & $\begin{array}{l}2 \cdot 1(0 \cdot 7-6 \cdot 5) \\
0.7(0 \cdot 3-2 \cdot 1) \\
1.9(0 \cdot 6-6 \cdot 0) \\
2 \cdot 6(0 \cdot 9-7 \cdot 7) \\
1.7(1 \cdot 2-2 \cdot 6) \\
1.3(0 \cdot 7-2 \cdot 2) \\
1.3(0 \cdot 7-2 \cdot 2) \\
1.2(0 \cdot 6-2 \cdot 4) \\
0.9(0 \cdot 5-1 \cdot 7) \\
1.0(0 \cdot 6-1 \cdot 6) \\
1.0(0.5-2 \cdot 0) \\
1.5(0.7-2 \cdot 8)\end{array}$ & 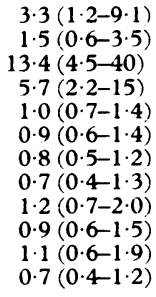 \\
\hline
\end{tabular}

ॠEye irritation or swollen eyelids.

+Nasal catarrh, blocked up nose, dry or sore throat or irritative cough.

†czema, facial itching, facial rash, itching or rashes on the hands.

$\$$ Headache, abnormal tiredness, sensation of getting a cold or nausea.

Odds ratio was calculated for the extremes of this continuous variable ranging from 0 to 1 .

iAt work during the last three months. 
A relation between current exposure to urban environments and airway symptoms was found even when controlling for confounders such as tobacco smoking, atopy, and occupational and residential exposure. This indicates that air pollution in the urban environment from vehicle exhausts or industrial pollution may be of significance for the SBS syndrome. In urban areas a higher prevalence of asthma and rhinitis in conscripts ${ }^{32}$ and a higher prevalence of respiratory symptoms in children ${ }^{31}$ has been reported. Air pollution from a paper pulp plant has also been shown to be related to hyperreactivity symptoms in children. ${ }^{30}$ To our knowledge, there are no earlier investigations showing a relation between the urban environment and SBS symptoms in adults.

We found a covariation between certain childhood exposures and SBS symptoms. The relation between spending childhood abroad and airway symptoms may be because many immigrants in Sweden come from warmer and more humid climate zones where mite allergies are more common than in the Nordic countries. ${ }^{42}$ The relation between urban childhood and general symptoms indicates that factors exist related to an urban childhood that lead to persistent health impairments. An earlier investigation has shown a relation between traffic intensity and the concentration of lead in deciduous trees. ${ }^{28} \mathrm{~A}$ relation between environmental exposure to lead from traffic and neurobehavioural effects in children has also been found. ${ }^{29}$ This indicates that the relation may be due to earlier lead exposure, in utero or during childhood. The possibility, however, that persistent effects of non-chemical factors in the urban environment, such as more stress or less social control, are responsible for the observed difference, cannot be excluded.

The results suggest an effect of maternal but not paternal smoking during childhood on the prevalence of atopy, allergy to nickel and SBS symptoms in the adult population. This relation was significant even when adjusting for childhood exposure to the urban environment, which was related to maternal smoking. The lack of effect of paternal smoking could be explained by a more intensive environmental exposure from the mother, but it may also indicate that tobacco smoke exposure in utero rather than airborne exposure in childhood is responsible for the effects. The findings concerning atopy are in agreement with other findings showing that maternal smoking during pregnancy leads to an increased IgE concentration in cord blood and increases the risk for subsequent allergy.$^{23} \mathrm{We}$ are not aware of other studies on the relation between maternal smoking and SBS symptoms or contact allergies in adults. Female smoking has increased in Sweden during the period $1950-80 .^{43}$ Our results suggest that this increase could lead to an increase in atopy, contact allergy, and SBS symptoms in the generation born during this period. During the period 1969-80, an increase of some contact allergies, in particular allergy to nickel and cobalt, was seen in a Swedish study based on standardised patch testing. ${ }^{41}$ Although this increase could be explained by an increase of ear piercing, the effect of maternal smoking on the development of contact allergies could be another explanation. Our findings support the view that maternal smoking should be minimised. Also, as maternal smoking and degree of urbanisation were related to each other, these factors must be carefully controlled in epidemiological studies.

Several personal factors such as age, sex, marital state, occupational activity, educational level, obesity, and regular physical exercise were not related to SBS symptoms when controlling for other factors significantly related to the syndrome. Also, several factors related to the dwelling such as building age, population density, type of dwelling, material of the dwelling, mechanical ventilation, mould growth, moisture damage, or presence of house pets were not significantly related to SBS symptoms. In the home environment, only two factors were significantly related to SBS symptomsnamely, newly painted surfaces and presence of preschool children.

Chemical stimulation of the trigeminus or olfactorius nerves has been suggested as an explanation of the sick building syndrome. ${ }^{44}$ In two earlier studies, we have shown a relation between SBS symptoms and the total indoor concentration of volatile organic hydrocarbons in sick buildings ${ }^{14}$ and in primary schools. ${ }^{15}$ Sensory nerve stimulation may also occur in industrial environments, and a good correlation between TLV values and irritative response in animal tests has earlier been shown. ${ }^{45}$ In the present study, we found no relation between current or earlier occupational exposure to chemicals and SBS symptoms when controlling for significant personal factors and non-occupational exposures. This may be due to selection mechanisms in adolescence causing sensitive persons to avoid exposed jobs or to the fact that current exposure levels are fairly low in Swedish workplaces. The last view is supported by the fact that no occupation in our sample could be classified as having a current average exposure above the present TLV values. Our findings agree with an earlier study comparing SBS symptoms in sick buildings and polluted industrial environments and in unexposed reference groups, ${ }^{12}$ which suggested that the modern non-industrial indoor environment may induce more symptoms than current industrial environments. The finding of a positive relation between current chemical exposure and a history of tobacco smoking agrees with another investigation, ${ }^{46}$ and shows the importance of controlling for smoking habits in occupational epidemiology.

The results indicate an effect of residential exposure to newly painted surfaces on airway symp- 
toms. Paint contains different types of volatile organic hydrocarbons that continue to be emitted into the environment after painting. In the past, indoor paint contained high concentrations of organic solvents, mostly non-polar compounds such as toluene, xylene, or white spirit. Nowadays, water soluble paints are used in most indoor painting in Sweden. ${ }^{47}$ Such paints contain mostly polar organic solvents at low concentrations and occupational measurements have shown that several components such as glycols, glycol ethers, white spirit, ammonia, formaldehyde, acrylate monomers, and higher esters are emitted to the air both during painting and months after the painting is finished. ${ }^{48}{ }^{49}$ Volatile organic compounds from fresh paint in dwellings may induce airway irritation. The findings in the present study are in agreement with earlier investigations in schools ${ }^{15}$ and sick buildings, ${ }^{214}$ showing a relation between SBS symptoms and indoor concentration of volatile organic compounds.

More than a fourth of the total work force used VDUs, and a relation between such work and eye and dermal symptoms was found, even when controlling for other factors such as atopy, allergy to nickel, static electricity, and psychosocial factors. A relation between VDU terminal work and dermal symptoms $\mathrm{s}^{5051}$ and mucosal irritation ${ }^{8}$ has been shown. Electrostatic fields may be generated from VDUs and may lead to an enhanced accumulation of dust. ${ }^{52}$

Wall to wall carpeting might be related to both electrostatic shocks ${ }^{513}$ and SBS symptoms. ${ }^{13}$ In two earlier studies, ${ }^{1114}$ a relation between static electricity and SBS symptoms has been shown. In two other studies in office workers, however, no such relation was shown. ${ }^{35}$ We found a higher prevalence of eye symptoms among subjects who often experienced electrostatic shocks, even when controlling for other factors. As we lack information on presence of wall to wall carpets, we cannot exclude the possibility that the effect may be due partly to the presence of such carpets. In conclusion, indications exist for a relation between static electricity and SBS symptoms, but it is still unclear to what extent this is causal, and at what levels of electrostatic charge symptoms are induced.

The psychosocial climate at work, measured by a psychosocial dissatisfaction index, was related to general symptoms. In two other investigations ${ }^{14} 15$ this index has been shown to be related to both prevalence and incidence of SBS. A further analysis showed that work satisfaction and climate of cooperation but not stress at work were related to symptoms. In earlier studies, psychosocial factors were shown to be related to general symptoms. ${ }^{811} \mathrm{We}$ could also show a relation between climate of cooperation at work and eye symptoms. This agrees with the results of a study on Danish office workers, in which a relation was found between psychosocial factors and mucosal irritation. ${ }^{8}$
One aim of our study was to explore relations between SBS symptoms and environmental factors in a broader sense than reported in current publications on SBS. Some of our results support earlier findings suggesting that indoor concentrations of volatile hydrocarbons, VDU work, static electricity, and psychosocial factors play an important part in the development of SBS. Also, the results indicate that environmental exposures in childhood, as well as from those currently found outdoors should be taken into consideration in epidemiological investigations on SBS. Preventive measures intended to reduce the prevalence of SBS should not exclusively focus on indoor air problems in new office buildings, but should also take other possible exposures and personal factors into account.

1 Akimenko VV, Andersen I, Lebowitz MD, Lindvall T. The "sick" building syndrome. In: Berglund $B$, Berglund $U$, Lindvall T, Sundell J, eds. Indoor air Vol 6 Evaluation and conclusions for health sciences and technology. Stockholm: Swedish Council for Building Research, 1986:87-97. (D13.)

2 Berglund B, Johansson I, Lindvall T, Lundin L. A longitudinal study of perceived air quality and comfort in a sick library building. In: Indoor air 90. Vol 1 Proceedings of the fifth international conference on indoor air and climate. Toronto, Canada. Ottawa: International conference on indoor air quality and climate, 1990:489-94.

3 Burge S, Hedge A, Wilson S, Bass JH, Robertson A. Sick building syndrome: a study of 4373 office workers. Ann Occup Hyg 1987;31:493-504.

4 Finnegan MJ, Pickering CAC, Burge PS. The sick building syndrome: prevalence studies. $\mathrm{Br}$ Med J 1984;289:1573-5.

5 Göthe C-J, Ancker K, Bjurström R, Holm S, Langworth S. Electric potential differences against the surroundings and discomforts in indoor environments. Ann Occup Hyg 1989;33:263-7.

6 Jaakola JJK, Heinonen OP, Seppänen O. Sick building syndrome, sensation of dryness and thermal comfort in relation to room temperature in an office building: need for individual control of temperature. Environment International 1989;15:163-8.

7 Skov P, Valbjörn O, Danish indoor climate study group et al. The "sick" building syndrome in the office environment: The Danish town hall study. Environment International 1987;13:339-49.

8 Skov P, Valbjörn O, Pedersen BV, Danish indoor climate study group, et al. Influence of personal characteristics, job-related factors and psychosocial factors on the sick building syndrome. Scand J Work Environ Health 1989;15:286-95.

9 Taylor PR, Dell'Acqua BJ, Baptiste MS, Hwang H-L, Sovik RA. Illness in an office building with limited fresh air access. $J$ Environ Health 1984;47:24-7.

10 Turiel I, Holowell CD, Miksch RR, Rudy JV, Young RA, Coye $M J$. The effects of reduced ventilation on indoor air quality in an office building. Atmospheric Environment 1983;17:51-64.

11 Michel I, Norbäck D, Edling C. An epidemiologic study of the relation between symptoms of fatigue, dental amalgam and other factors. Swed Dent J 1989;13:33-8.

12 Norbäck D, Rand G, Michel I, Amcoff S. The prevalence of symptoms associated with sick buildings and polluted industrial environments as compared to unexposed reference groups without expressed dissatisfaction. Environment International 1989;15:85-94

13 Norbäck $D$, Torgen $M$. A longitudinal study relating carpeting with sick building syndrome. Environment International 1989;15:129-35.

14 Norbäck D, Michel I, Widström J. Indoor air quality and personal factors related to the sick building syndrome. Scand $J$ Work Environ Health 1990;16:121-8.

15 Norbäck D, Torgen $M$, Edling C. Volatile organic compounds, respirable dust, and personal factors related to prevalence and incidence of sick building syndrome in primary schools. $\mathrm{Br} \mathrm{J}$ Ind Med 1990;47:733-41. 
16 Mölhave $\mathrm{L}$, Bach $\mathrm{B}$, Pedersen OF. Human reactions to low concentrations of volatile organic compounds. Environment International 1986;12:167-75.

17 Skov P, Valbjörn O, Pedersen BV, Danish Indoor Climate Study Group. Influence of indoor climate on the sick building syndrome in an office environment. Scand $J$ Work Environ Health 1990;16:363-71.

18 Robertson AS, Burge PS, Hedge A, Wilson S, Harris-Bass J. Relation between passive smoke exposure and "building sickness." Thorax 1988;43:263.

19 Holmberg $\mathrm{K}$. Indoor mould exposure and health effects. In: Seifert B, Esdorn H, Fischer M, Ruden H, Wegner J, eds. Indoor air ' $87 \mathrm{Vol} 1$. Volatile organic compounds, combustion gases, particles and fibers, microbiological agents. Berlin: Institute for water, soil and air hygiene, 1987:637-42.

20 Waegemaekers $M$, Van Wageningen $N$, Brunekreef B, Boleij JSM. Respiratory symptoms in damp houses. Allergy 1989;44:192-8.

21 Valbjörn $\mathrm{O}$, Kousgărd $\mathrm{N}$. Headache and mucus membrane irritation an epidemiological study. In: Berglund B, Lindvall $\mathrm{T}$, Sundell J, eds. Indoor air Vol 2. Radon, passive smoking, particulates and housing epidemiology. Stockholm: Swedish Council for Building Research, 1984:249-54. (D17.)

22 Pukander K, Luotonen J, Timonen M. Risk factors affecting the occurrence of acute otitis media among 2-3-year old urban children. Acta Otolaryngol (Stockh) 1985;100:260-5.

23 Magnusson CG. Maternal smoking influences cord serum IgE and IgD levels and increases the risk for subsequent infant allergy. J Allergy Clin Immunol 1986;78:898-904.

24 Martinez FD, Antognoni G, Macri F, et al. Parental smoking enhances bronchial responsiveness in nine-year-old children. Am Rev Respir Dis 1988;138:518-23.

25 Schenker MB, Samet JM, Speizer FE. Risk factors for childhood respiratory disease. Am Rev Respir Dis 1983;128:1038-43.

26 Stålberg $M-R$, Ruuskanen O, Virolainen E. Risk factors for recurrent otis media. Pediatric Infectious Disease 1986;5:30-2.

27 Kero P, Piekkala P. Factors affecting the occurrence of acute otitis media during the first year of life. Acta Paediatr Scand 1987;76:618-23.

28 Lyngbye T, Hansen O, Grandjean P, Trillingsgard A, Beese I Traffic as a source of lead exposure in childhood. Sci Total Environ 1988;71:461-7.

29 Ericson JE, Mishra SI. Soil lead concentrations and prevalence of hyperactive behaviour among school children in Ottawa, Canada. Environment International 1990;16:247-56.

30 Andrae S, Axelson O, Björksten B, Fredriksson M, Kjellman NI M. Symptoms of bronchial hyperreactivity and asthma in relation to environmental factors. Arch Dis Child 1988;63:473-8.

31 Spinaci S, Arossa W, Bugiani M, Natale P, Bucca C, de Candussio $G$. The effects of air pollution on the respiratory health of children: a cross-sectional study. Pediatr Pulmonol 1985;1:262-6.

32 Aberg N. Asthma and allergic rhinitis in Swedish conscripts. Clinical and Experimental Allergy 1989;19:59-63.

33 Bengtsson C, Hulten B, Larsson B, Noppa H, Steen B, Warnold $\mathrm{J}$. New weight-height tables in Swedish middle aged and elderly men and women. Lakartidningen 1981;98:3142-4. (In Swedish, summary in English.)
34 Nordic Standard Classification of Occupations. Stockholm: National Swedish Labour Market Board, 1983. (NYK82.)

35 National Swedish Board of Occupational Safety and Health. Code of statutes. Stockholm: 1987 (AFS12) (in Swedish.)

36 Statistical Abstract of Sweden 1988;74:181.

37 Coultas DB, Peake GT, Samet JM. Questionnaire assessment of lifetime and recent exposure to environmental tobacco smoke. Am J Epidemiol 1989;130:338-47.

38 Sandler DP, Shore DL. Quality data on parents' smoking and drinking by adult offspring. Am J Epidemiol 1986;124:768-78.

39 Östlin P. Occupational career and health. Methodological considerations on the healthy worker effect. Uppsala: Acta Universitatis Upsaliensis. Comprehensive Summaries of Uppsala Dissertations from the Faculty of Medicine 1989;224:1-56. (Thesis.)

40 Greenland S. Modeling and variable selection in epidemiologic analysis. Am J Publ Health 1989;79:340-9.

41 Edman $B$, Halvor $M$. Trends and forecasts for standard allergens in a 12-year patch test material. Contact Dermatitis 1982;8: 95-104.

42 Charpin D, Vervloet D, Charpin J. Epidemiology of asthma in western Europe. Allergy 1988;43:481-92.

43 The Swedish Committee for Tobacco Control. Tobakslagen, betänkande ar tobaksutredningen (The new tobacco act, a proposal by the Swedish committee for tobacco control). Stockholm: Statens Offentliga Utredningar 1990:29. (In Swedish with abstract in English.)

44 Berglund B, Lindvall T. Sensory reactions to "sick buildings." Environment International 1986;12:147-59.

45 Alarie Y. Bioassay for evaluating the potency of airborne sensory irritants and predicting acceptable levels of exposure in man. Federation of Cosmetic Toxicology 1981;19:623-6.

46 Stellman SD, Boffetta P, Garfincel L. Smoking habits of 800000 American men and women in relation to their occupation. $\mathrm{Am}$ $J$ Ind Med 1988;13:43-58.

47 Wieslander G, Edling C, Bolin S. Airway symptoms and dermal symptoms in painters predominantly working with waterbased paints. Hygiea 1989;98:119. (In Swedish.)

48 Hansen MK, Larsen M, Cohr K-H Waterborne paints: A review of their chemistry and toxicology and the result of determinations made during their use. Scand $J$ Work Environ Health 1987;13:473-85.

49 Clausen PA, Wolkoff P, Nielsen PA. Off-gassing from water dilutable paints; contribution to indoor air pollution. In: Proceedings of the 37 th Nordic meeting of work environment. Gothenburg 1988. Stockholm: National Institute of Work environment, 1988:73-4. (In Swedish.)

50 Liden C, Wahlberg JE. Does visual display terminal work provoke rosacea? Contact Dermatitis 1985;13:235-41.

51 Linden V, Rolfsen S. Video computer terminals and occupational dermatitis. Scand $J$ Work Environ Health $1981 ; 7: 62-7$.

52 Olsen WC. Electric field enhanced aerosol exposure in visual display unit environments. Bergen, Norway: Chr Michelsen Institute 1981. (CMI No 803604-1.)

Accepted 26 November 1990 